
\title{
25 Research Soure \\ Thermography as a Non-ionizing Quantitative Tool for Diagnosing Endo-perio Lesions
}

\section{Atef Aboushady}

Future University in Egypt

Wael Talaat ( $\nabla$ wtaha@sharjah.ac.ae)

University of Sharjah College of Dentistry https://orcid.org/0000-0002-5784-3784

\section{Zaid Hamdoon}

University of Sharjah College of Dentistry

\section{Tarek Elshazly}

University of Bonn, School of Dentistry

\section{Nivin Ragy}

Future University in Egypt

\section{Christoph Bourauel}

University of Bonn, School of Dentistry

\section{Sameh Talaat}

University of Bonn, School of Dentistry

\section{Research article}

Keywords: Thermography, acute pulpitis with apical periodontitis, acute periapical abscess, chronic periapical abscess, endo-perio intraoral lesions

Posted Date: March 19th, 2021

DOI: https://doi.org/10.21203/rs.3.rs-329327/v1

License: (c) (1) This work is licensed under a Creative Commons Attribution 4.0 International License.

Read Full License 


\section{Abstract}

Background: Thermography is a contemporary imaging modality based on acquiring and analyzing thermal data using non-contact devices. The aim of the present study was to assess the validity of thermography, compared with that of the gold standard, for the diagnosis of endo-perio lesions and to evaluate the temperature ranges for acute pulpitis with apical periodontitis (AAP), acute periapical abscess (AA) and chronic periapical abscess (CA).

Methods: AAP, AA and CA were diagnosed based on clinical and radiographic criteria. Thermographic data were acquired using the FLIR E-5 Infrared Camera. Extraoral thermal images were taken from the front and right and left sides of patients whose mouths were closed, and one intraoral thermal image was taken from the palatal perspective. Agreement in the diagnoses based on the combination of clinical and radiographic assessments and the thermographic evaluation was calculated. The temperature ranges of the three subdiagnostic groups were also measured.

Results: A total of 80 patients were enrolled in this study. The mean thermal image temperature for $A A$ was $37.26 \pm 0.36$, that for CA was $35.03 \pm 0.63$ and that for AAP was $36.07 \pm 0.45$. The differences between the mean thermal temperatures of the three diagnostic groups were highly statistically significant $(P<0.001)$. The result of the Kappa coefficient of agreement between the combination of clinical and radiographic assessments and the thermographic evaluation was highly significant $(P<0.001)$. The rates of change in temperature with time for each diagnostic group were highly statistically significantly different $(P<0.001)$.

Conclusions: Thermography is an effective, quantitative and nonionizing approach that can be used for the diagnosis of endo-perio lesions. This technology is able to distinguish different forms of infection by identifying the range of temperature increases related to each form.

\section{Background}

Endo-perio intraoral lesions result from pulpal lesions or disrupted periodontal attachments that extend to the apex, furcation or lateral canals. Endo-perio lesions are usually consequences of the vascular and anatomic connections between the pulp and periodontium. A thorough history and careful clinical and radiographic examinations are required to diagnose such lesions and develop a treatment plan. However, the diagnosis of endo-perio lesions is always a challenge, even for experienced dental practitioners, due to the multifactorial origin of these lesions, which include diverse interactions between different strains and species of microbes ${ }^{1}$.

Thermography is a contemporary imaging modality with various potential applications in dentistry. The technology is based on the acquisition and analysis of thermal data using noncontact devices, and it depends on infrared electromagnetic radiation, which is emitted by objects with temperatures above absolute zero ${ }^{2}$. Temperature differences can be charted on a two-dimensional image, and accordingly, the temperatures of individual spots in an area of interest at a certain time can be recorded ${ }^{3}$. 
Human tissues are ideal emitters of infrared radiation at room temperature. It has been reported that most of the infrared radiation emitted by the human body has long wavelengths $(8-15 \mu \mathrm{m})$. Infrared cameras can convert the emitted radiation into electrical signals, which can then be displayed using colors to represent temperature values. Ultimately, a quantitative temperature map of the area of interest is produced, and this map can be utilized to identify different pathological conditons ${ }^{4}$.

Thermography has been used in different applications in dentistry. Chronic orofacial pain and temporomandibular disorders were successfully classified thermally ${ }^{5,6}$. Thermography has been used to evaluate thermal insults to the dental pulp. Thermal image analysis showed that the pulpal temperature increased significantly following the electrothermal debonding of orthodontic brackets, confirming the high risk to the pulp ${ }^{7}$. Thermophotonic lock-in imaging using photothermal wave principles has been used to detect early dental carious lesions ${ }^{8}$. Moreover, thermography has been used successfully to detect malignancies of human hard and soft tissues ${ }^{9,10}$.

The aims of the present study were to assess the validity of thermography for the diagnosis of endo-perio lesions and to compare it with the gold standard, $\mathrm{X}$-ray radiographs. The temperature ranges for acute pulpitis with apical periodontitis lesions and acute and chronic periapical abscess lesions were evaluated.

\section{Methods}

The study was conducted on patients who were treated at the Oral Diagnosis Clinic at the Faculty of Oral and Dental Medicine, Future University, Egypt, between September 2017 and March 2020. All the patients underwent comprehensive dental, intraoral, and extraoral diagnostic examination procedures. Patients were included in the study if they had any signs or symptoms of swelling, tenderness with palpation, pain with percussion, widening of the lamina dura or radiolucency related to the apex of the tooth. The exclusion criteria included an age under 18 years or over 60 years; inflammatory conditions of the oral mucosa; severe cognitive, mental and locomotive deficiencies; physiological or pathological conditions associated with changes in thermal homeostasis; smoking habits and the use of nonsteroidal anti-inflammatory drugs.

All the patients were informed of the aim of the study, and they signed a formal consent form before participation.

Ethical approval for this study was obtained from the Research Ethics Committee at Future University, Egypt.

The guidelines of the Declaration of Helsinki were followed in this investigation.

AAP, AA and CA were diagnosed based on clinical and radiographic criteria. The clinical examination involved the observation of decayed and broken restorations, fracture lines, swelling and sinus tracks. Tenderness of the apical area upon palpation, percussion tests, pulp sensitivity tests and tooth mobility evaluations were also performed. The radiographic diagnosis was based on the identification of areas of 
radiolucency on periapical radiographs. The clinical and radiographic examinations were performed by two calibrated investigators with over 10 years of clinical experience.

Thermographic investigation:

Thermographic data were acquired using the FLIR E-5 Infrared Camera with MSX (FLIR Systems, Oregon, USA). Images were stored on a memory card in the TIFF file format and processed using specialized software (FLIR Tools Thermal Analysis and Reporting; Desktop, FLIR Systems, Oregon, USA). The camera was calibrated considering the emissivity parameters of the human body ( $\varepsilon=0.98$ and $\lambda \otimes 2 \mu \mathrm{m})$ and the ambient conditions (humidity and temperature), and a thermal range from $20^{\circ} \mathrm{C}$ to $250^{\circ} \mathrm{C} \pm 2^{\circ} \mathrm{C}$, a pixel infrared resolution of 10,800 (120x90), and adequate shade were selected for optimal color registration. A standard protocol was used by positioning all the electronic devices at least 2 meters from the patient, covering windows and reflective surfaces with opaque dark textiles and turning off artificial light sources. Room temperature was set to $20 \pm 1^{\circ} \mathrm{C}$, and the air currents were directed away from the patient and toward the periphery of the room. The patients were asked to refrain from smoking, eating and drinking for 60 minutes prior to the examination, and they remained at rest for 10 minutes before the procedure. The oral cavity was cooled by rinsing with cold water $\left(10^{\circ} \mathrm{C}\right)$ for 1 minute.

A profile-guided thermography scanner was designed to provide a guided trajectory for the infrared camera using a machined profile, which was designed as an offset contour of the human mandible to maintain the camera in a position such that it faced the patient. Bearing housing was designed to roll on the guide holding the camera, and upper and lower bearings were used to hold the positioning mechanism and the camera, while side bearings were used to adjust the camera angle to face the patient (Fig. 1).

Extraoral thermal view images were taken from the front and right and left sides of patients whose mouths were closed. After that patients rinsed their mouths with cold water, five images were recorded from each view at one-minute intervals. One intraoral thermal image was taken from the palatal perspective at a distance of $20 \mathrm{~cm}$. The images on each side were taken 5 minutes after the patient rinsed with cold water (Fig. 2).

Thermographic data recording was performed by a third investigator who was blinded to the clinical and radiographic patient records. Agreement in the diagnoses of AAP, AA and CA based on the combination of clinical and radiographic assessments and the thermographic evaluation was calculated to assess the validity of thermography. The temperature ranges of the three subdiagnostic groups were also measured.

\section{Statistical analysis}

The data analysis was performed using the Statistical Package for Social Sciences (SPSS) version 16.0 (SPSS Inc., Chicago, IL, USA). The thermography results are expressed as the mean \pm standard deviation (SD). Analysis of variance (ANOVA) was used for the analysis of between-group and within-group differences. The Bonferroni method was used for multiple comparisons. The Kappa coefficient of 
agreement was used to assess the relation between the combination of clinical and radiographic assessments and the thermographic evaluation. Chi-squared test was used for categorical data. P-values of $<0.05$ were considered statistically significant.

\section{Results}

A total of 80 patients ( 42 females and 38 males) were enrolled in this study. Twenty-seven patients with a mean age of $37.37 \pm 9.97$ years were diagnosed with AA, 29 patients with a mean age of $39.1 \pm 12.34$ years were diagnosed with $C A$, and 24 patients with a mean age of $36.96 \pm 10.98$ years were diagnosed with AAP.

The mean thermal image temperature for AA was $37.26 \pm 0.36$, that for CA was $35.03 \pm 0.63$ and that for AAP was $36.07 \pm 0.45$. The results of the analysis of variance (ANOVA) for the assessment of betweengroup and within-group differences were highly statistically significant $(P<0.001)$. The differences between the mean thermal image temperatures of the three diagnostic groups were highly statistically significant $(P<0.001)$ (Table 1).

Table 1

Differences between the mean values of the thermal images' temperatures of the three diagnostic groups

\begin{tabular}{|c|c|c|c|c|c|c|}
\hline \multicolumn{2}{|c|}{$\begin{array}{l}\text { Investigators' } \\
\text { diagnosis }\end{array}$} & \multirow{2}{*}{$\begin{array}{l}\text { Mean } \\
\text { Difference }\end{array}$} & \multirow{2}{*}{$\begin{array}{l}\text { Standard } \\
\text { Error }\end{array}$} & \multirow{2}{*}{$\begin{array}{l}P \\
\text { value }\end{array}$} & \multicolumn{2}{|c|}{ 95\% Confidence Interval } \\
\hline & & & & & $\begin{array}{l}\text { Lower } \\
\text { Bound }\end{array}$ & $\begin{array}{l}\text { Upper } \\
\text { Bound }\end{array}$ \\
\hline AA & CA & 2.2 & 0.1 & $<.001$ & 1.9 & 2.6 \\
\hline AA & AAP & 1.2 & 0.1 & $\begin{array}{l}< \\
0.001\end{array}$ & 0.8 & 1.5 \\
\hline AAP & $\mathrm{CA}$ & 1.0 & 0.1 & $<.001$ & 0.7 & 1.4 \\
\hline
\end{tabular}

The Kappa coefficient of agreement (0.970) between the combination of clinical and radiographic assessments and the thermographic evaluation was highly significant $(P<0.001)$.

The rates of change in temperature with time for each diagnostic group were highly statistically significantly different $(P<0.001)$ (Fig. 3).

\section{Discussion}

Thermography is an imaging modality with a promising future in dental medicine. There are many advantages of thermography, including the possibility of evaluating different diseases without the use of ionizing radiation, which prevents many of the harmful effects of radiation and allows disease evaluation during pregnancy. In addition, thermography is a noncontact technology and is optimal for infection 
control. Thermography allows the comparison of different areas of interest on two-dimensional images and allows the evaluation to be conducted in real time ${ }^{11}$. The concept behind the use of thermography to aid in the diagnosis of pathologies is based on the fact that heat is always generated in response to inflammation, and thermography images are able to quantify the surface temperature, thus providing an assessment of the microcirculation in a specific area. It has been reported that a temperature difference of more than $3^{\circ} \mathrm{C}$ usually indicates infection ${ }^{12}$. Furthermore, thermography is able to distinguish between different infections based on the range of temperature increases associated with each ${ }^{13}$. In the present study, the temperature ranges for each diagnostic group were identified, and the differences between the mean temperatures of the three diagnostic groups were highly statistically significant. In another study that evaluated the thermal image temperatures for facial cellulitis and dental abscess, a significant temperature difference between the two pathologic conditions was observed. However, the authors reported a small sample size as a limitation of their study ${ }^{14}$. The capability of thermography for distinguishing the temperature ranges of different pathological conditions can be attributed to recent advancements in technology. The new generation of high-resolution cameras has the ability to detect even minor temperature changes resulting from different pathological conditions. These changes can result from the distinctive pathophysiological pathways of the different pathologies, which might still have a general inflammatory origin. At the beginning of the inflammatory process, the somatic-vegetative reflex of the adrenal gland is activated. This is usually followed by the secretion of histamine and kinins, which lead to local decreases in vascular resistance. Liver metabolic processes then produce acute phase proteins and clotting cascade proteins, leading to muscle protein proteolysis and fever. Increased permeability of the blood vessel endothelium, which leads to a movement of water to the perivascular space, usually occurs within the first hour following stimulation ${ }^{15}$. Edema and reddening usually follow due to the difficulty of capillary blood outflow from the site of inflammation, leading to passive hyperemia. The secretion of endogenic pyrogens such as interleukin 1 and tumor necrosis factor, excitation of the sympathetic system and increase in adrenal glucocorticoid levels lead to a febrile state. These changes, together with changes in the metabolic state of the inflammatory site, lead to a local increase in temperature ${ }^{16}$.

In the present study, the rates of change in temperature with time for each diagnostic group were highly statistically significantly different. The gradual increase in thermographic temperatures has been shown to be correlated with the gradual increase in the concentrations of inflammatory mediators, which peak 96 hours after the start of inflammation ${ }^{17}$. The results of the present study support the hypothesis that thermography might be able to detect the inflammatory reaction during the preclinical stage, leading to early diagnosis ${ }^{18}$. Thus, digital infrared imaging may be able to promote the early diagnosis of inflammatory conditions, even before clinical symptoms are observed ${ }^{19}$.

\section{Conclusions}

Thermography is an effective, quantitative and nonionizing approach that can be used for the diagnosis of endo-perio lesions. This technology is able to distinguish different forms of infection by identifying the 
range of temperature increases related to each form. Thermography might be able to detect inflammatory reactions during the preclinical stage, leading to early diagnosis.

\section{Abbreviations}

AAP

acute pulpitis with apical periodontitis.

AA

acute periapical abscess.

CA

chronic periapical abscess.

\section{Declarations}

Funding: This research did not receive any specific grant from funding agencies in the public, commercial, or not-for-profit sectors.

Competing interests: The authors declare that they have no competing interests.

Ethics approval and consent to participate: This study was performed in line with the principles of the Declaration of Helsinki. Approval was granted by the Research Ethics Committee at the Future University in Egypt, Cairo, Egypt (FUE.REC (15)/12-2017). Written informed consents were obtained from all individual participants included in the study.

Consent for publication: Consent for publication was obtained from all relevant individuals.

Availability of data and materials: The datasets used and/or analysed during the current study are available from the corresponding author on reasonable request.

Acknowledgements: Not applicable

Authors' contributions: Study conception and design: MAA, CB, ST; data collection: MAA, WT, ZH, TME, $\mathrm{NR}, \mathrm{CB}, \mathrm{ST}$; analysis and interpretation of results: MAA, WT, ZH, TME, NR, CB, ST; draft manuscript preparation: MAA, WT, ZH, TME, NR, CB, ST. All authors reviewed the results and approved the final version of the manuscript.

\section{References}

1. Ahmed HM. Different perspectives in understanding the pulp and periodontal intercommunications with a new proposed classification for endo-perio lesions. ENDO (Lond Engl) 2012;6:87-104.

2. Zakian CM, Taylor AM, Ellwood RP, Pretty IA. Occlusal caries detection by using thermal imaging. J Dent 2010;38(10):788-795. doi: 10.1016/j.jdent.2010.06.010. 
3. Saxena AK, Willital GH. Infrared thermography: experience from a decade of pediatric imaging. Eur $\mathrm{J}$ Pediatr 2008;167(7):757-64. doi: 10.1007/s00431-007-0583-z.

4. Chan $C P$, Lin $C P$, Tseng $S C$, Jeng JH. Vertical root fracture in endodontically versus nonendodontically treated teeth: a survey of 315 cases in Chinese patients. Oral Surg Oral Med Oral Pathol Oral Radiol Endod 1999;87(4):504-507. doi: 10.1016/s1079-2104(99)70252-0.

5. Gratt BM, Anbar M. Thermology and facial telethermography: Part II. Current and future clinical applications in dentistry. Dento maxillafac Radiol 1998;27:68-74.

6. Gratt BM, Graff-Radford SB, Shetty V, Solberg WK, Sickles EA. A 6-year clinical assessment of electronic facial thermography. Dentomaxillofac Radiol 1996;25:247-255.

7. Cummings M, Biagioni P, Lamey PJ, Burden DJ. Thermal image analysis of electrothermal debonding of ceramic brackets: an in vitro study. Eur J Orthod 1991;21: 111-118.

8. Tabatabaei N, Mandelis A, Amaechi BT. Thermophotonic lock-in imaging of early demineralized and carious lesions in human teeth. J Biomed Opt 2011;16(7):071402. doi: 10.1117/1.3564890.

9. Bonmarin M, Le Gal FA. Lock-in thermal imaging for the early-stage detection of cutaneous melanoma: a feasibility study. Comput Biol Med 2014;47:36-43. doi:

10.1016/j.compbiomed.2014.01.008.

10. Zhang H, Tavakolian P, Sivagurunathan K, Mandelis A, Shi W, Liu FF. Truncated-correlation photothermal coherence tomography derivative imaging modality for small animal in vivo early tumor detection. Opt Lett 2019;44(3):675-678. doi: 10.1364/OL.44.000675.

11. Sanchis-Sánchez E, Salvador-Palmer R, Codoñer-Franch P, Martín J, Vergara-Hernández C, Blasco J, Ballester E, Sanchis E, González-Peña R, Cibrián R. Infrared thermography is useful for ruling out fractures in paediatric emergencies. Eur J Pediatr 2015;174(4):493-9. doi: 10.1007/s00431-014-24250 .

12. Hildebrandt C, Raschner C, Ammer K. An overview of recent application of medical infrared thermography in sports medicine in Austria. Sensors (Basel) 2010;10(5):4700-4715. doi:10.3390/s100504700.

13. Zaproudina N, Varmavuo V, Airaksinen O, Närhi M. Reproducibility of infrared thermography measurements in healthy individuals. Physiol Meas 2008;29(4):515-524. doi: 10.1088/09673334/29/4/007.

14. Ammoush M, Gzawi M , Warawreh A, Hijazin R, Jafar H. Clinical evaluation of thermography as a diagnostic tool in oral and maxillo-facial lesions. JRMS 2018; 25(3):45-49. DOI: 10.12816/00532.

15. Yılmaz UN, Güneş Uysal RF, Dündar Yılmaz B, Tuncer MC. Histopathologic and immunohistochemical investigations of dental abscess formed in maxillofacial area. Folia Morphol (Warsz). 2019;78(4):754-761. doi: 10.5603/FM.a2019.0051.

16. Blomqvist A, Engblom D. Neural Mechanisms of Inflammation-Induced Fever. Neuroscientist. 2018;24(4):381-399. doi: 10.1177/1073858418760481.

17. Celeste CJ, Deschesne K, Riley CB, Theoret CL. Skin temperature during cutaneous wound healing in an equine model of cutaneous fibroproliferative disorder: kinetics and anatomic-site differences. Vet 
Surg. 2013 Feb;42(2):147-53. doi: 10.1111/j.1532-950X.2012.00966.x.

18. Pauk J, Wasilewska A, Ihnatouski M. Infrared thermography sensor for disease activity detection in rheumatoid arthritis patients. Sensors (Basel). 2019;19(16):3444. doi:10.3390/s19163444.

19. Adam M, Ng EYK, Tan JH, Heng ML, Tong JWK, Acharya UR. Computer aided diagnosis of diabetic foot using infrared thermography: A review. Comput Biol Med. 2017 Dec 1;91:326-336. doi: 10.1016/j.compbiomed.2017.10.030.

\section{Figures}




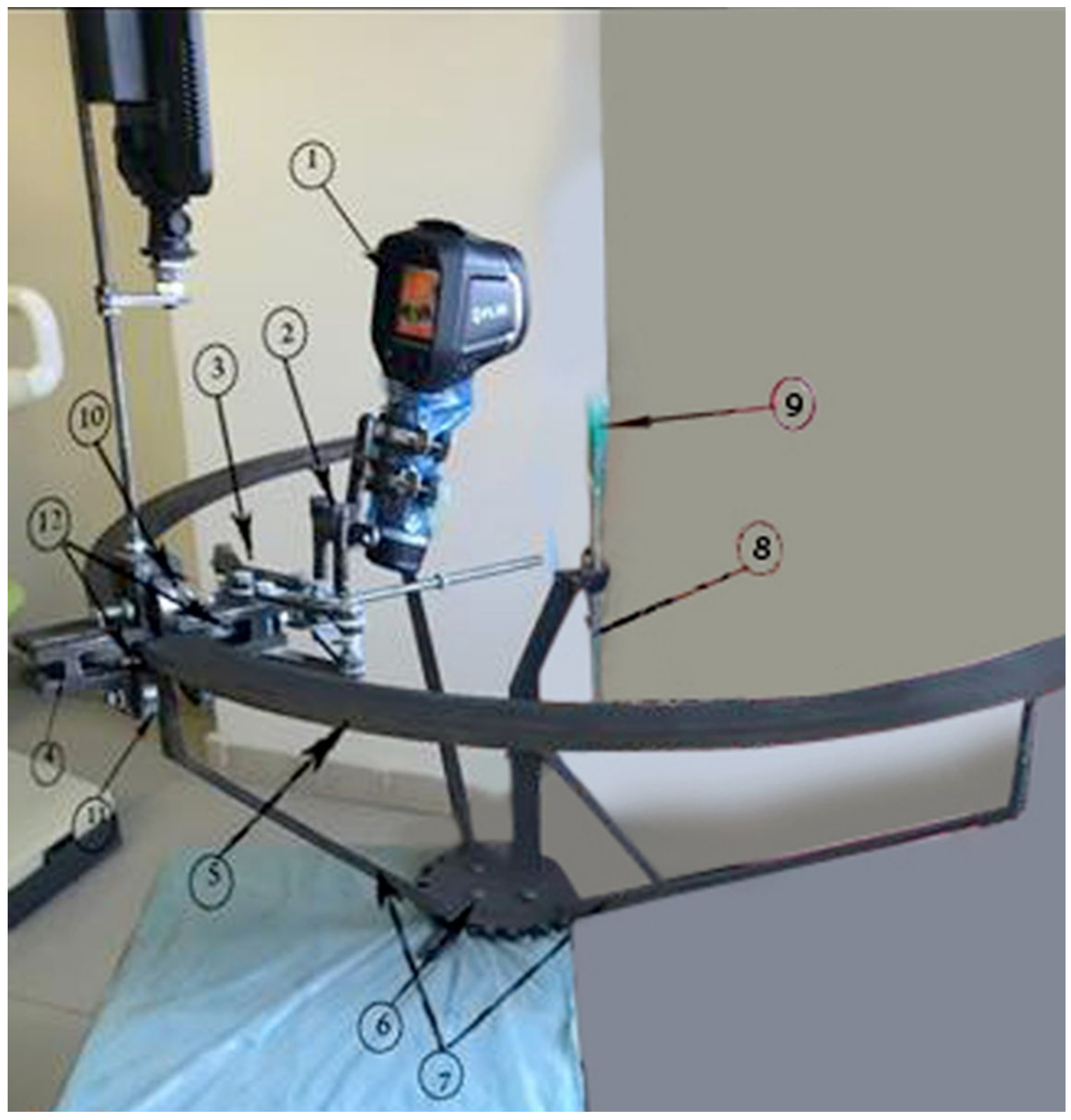

Figure 1

Profile-guided thermography scanner showing: 1. Infrared camera, 2. Adjusting angles, 3. Scissors mechanism, 4. Bearing housing, 5. Guiding profile, 6. Fixing flange, 7. Guide supports, 8. Chin rest support, 9. Chin rest, 10. Upper bearing, 11. Lower bearings, 12. Side bearings. 


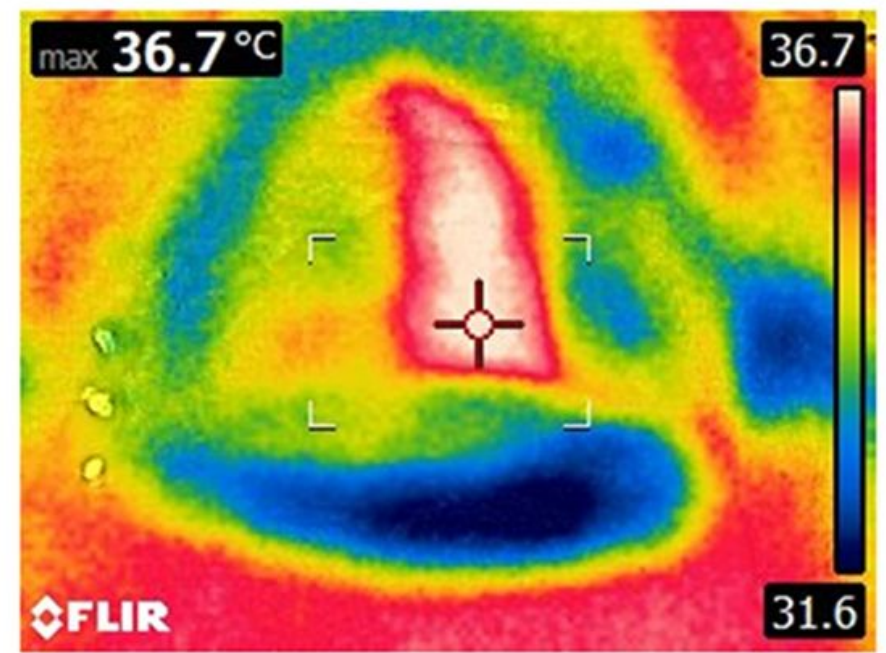

(a)

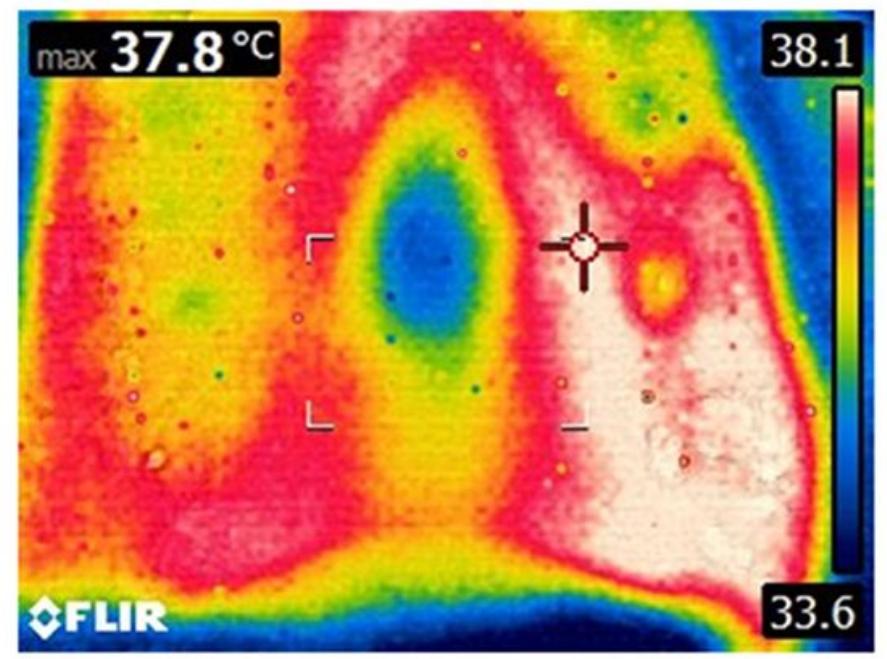

(c)

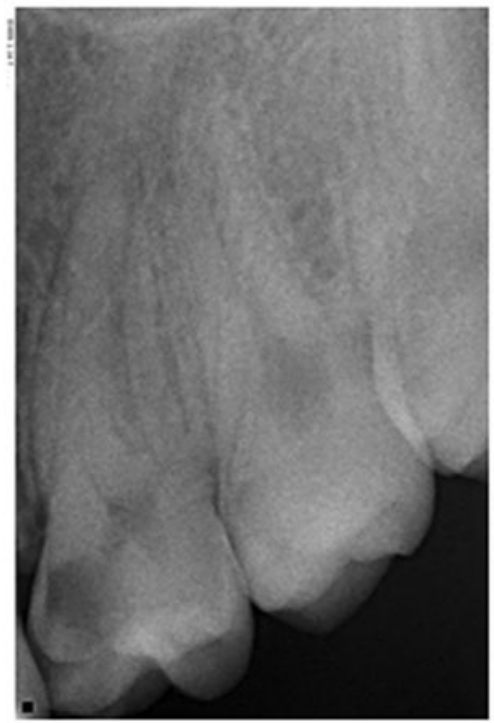

(b)

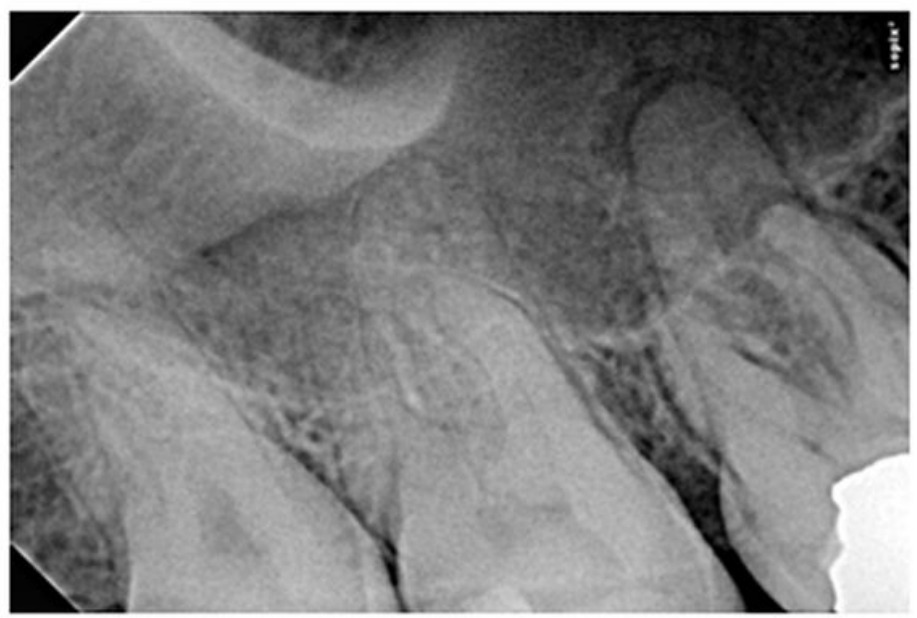

(d)

\section{Figure 2}

(a) Thermal image for $\mathrm{CA}$ related to the upper right second premolar captured after cooling the oral cavity by rinsing with cold water $\left(10^{\circ} \mathrm{C}\right)$ for 1 minute. The heat detector is indicating the highest temperature $\left(33.1^{\circ} \mathrm{C}\right)$. (b) Thermal image of the same lesion captured after 5 minutes. (c) Thermal image for AAP related to the upper left first molar. (d) Thermal image for AA related to the upper left first molar. 


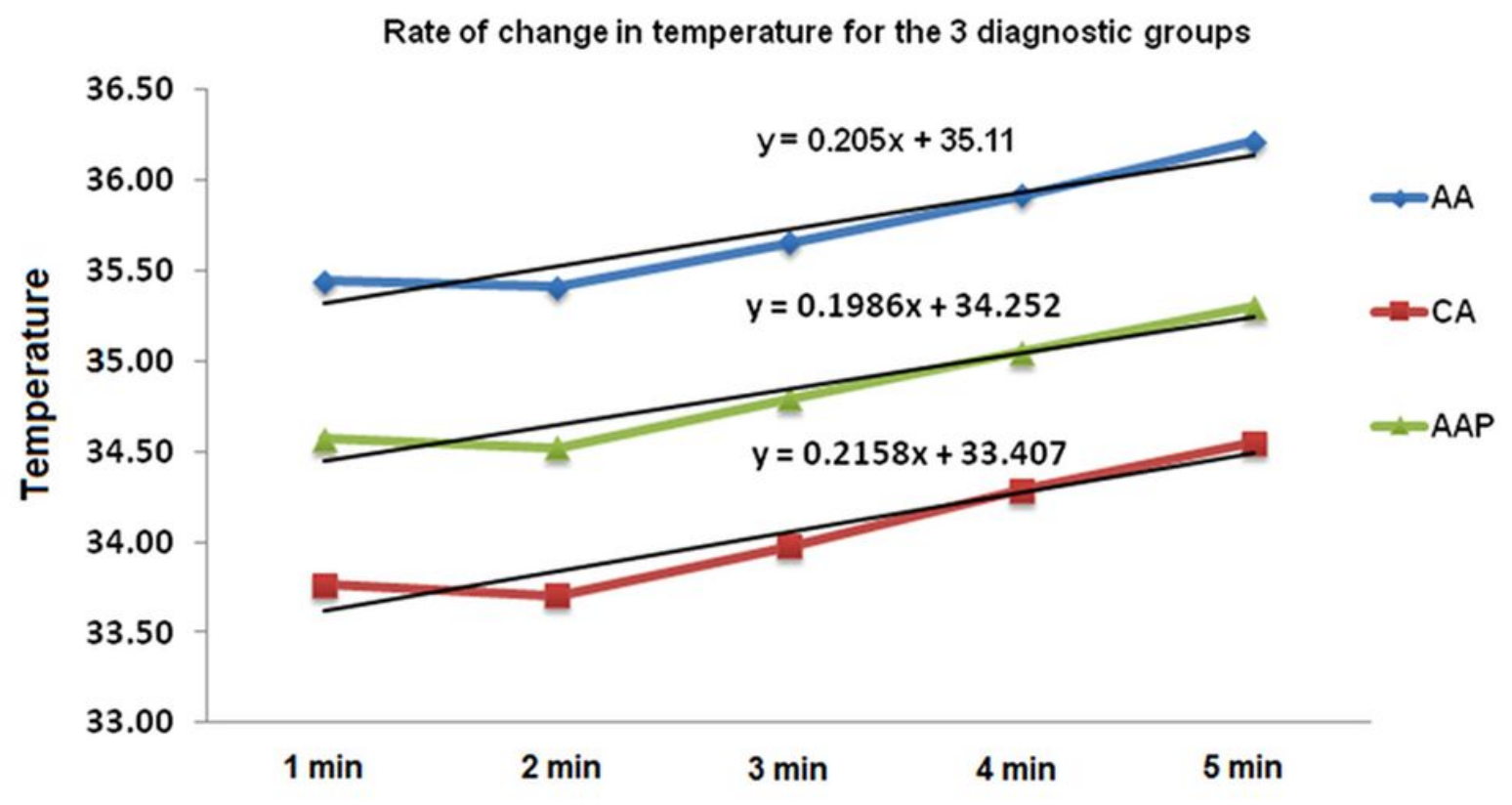

Figure 3

Rates of change in temperature for the 3 diagnostic groups. 